13,05

\title{
Влияние рН растворов на коэрцитивную силу и микроструктуру пленок СоР, полученных химическим осаждением
}

\author{
(c) А.В. Чжан ${ }^{1,2}$, С.А. Подорожняк ${ }^{1}$, М.Н. Волочаев ${ }^{3}$, Г.Н. Бондаренко ${ }^{4}$, Г.С. Патрин ${ }^{1,3}$ \\ ${ }^{1}$ Сибирский фредеральный университет, \\ Красноярск, Россия \\ ${ }^{2}$ Красноярский государственный аграрный университет, \\ Красноярск, Россия \\ ${ }^{3}$ Институт физики им. Л.В. Киренского ФИЦ КНЦ СО РАН, \\ Красноярск, Россия \\ ${ }^{4}$ Институт химии и химической технологии ФИЦ КНЦ СО РАН, \\ Красноярск, Россия \\ E-mail: avchz@mail.ru
}

(Поступила в Редакцию 20 декабря 2016 г.)

\begin{abstract}
Определены особенности изменения микроструктуры и коэрцитивной силы $H_{C}$ пленок СоР, полученных химическим осаждением, в зависимости от $\mathrm{pH}$ растворов. Установлено, что в области $\mathrm{pH} \sim 8.5$ происходит структурный переход пленки из субмикрокристаллического в нанокристаллическое состояние, который предшествует переходу пленки из кристаллической в аморфную фазу. Показано, что наблюдаемый переход происходит без изменения кристаллографической структуры кристаллитов и обусловлен уменьшением их геометрических размеров за счет внедрения атомов Р. Установлено, что пленки СоР, полученные в области $\mathrm{pH} \sim 8.5$, обладают свойствами, характерными для компактных нанокристаллических материалов.
\end{abstract}

Работа выполнена при частичной поддержке РФФИ (грант № 14-02-00238-a).

DOI: 10.21883/FTT.2017.07.44607.449

\section{1. Введение}

Тонкие магнитные пленки (ТМП) на основе сплавов Со и $\mathrm{P}$ находят широкое применение в самых разнообразных конструкторских решениях, что во многом связано с возможностью получения на их базе как высоко-, так и низкокоэрцитивных образцов [1]. Как известно, значение коэрцитивной силы $H_{C}$ в значительной степени зависит от кристаллической структуры пленки. На микроструктуру пленок СоР, полученных химическим способом, существенное влияние оказывают щелочные реагенты (гидрокарбонат натрия либо аммиак), введение которых приводит к изменению $\mathrm{pH}$ раствора и, как следствие, к изменению относительного содержания Со и Р в пленках [2]. В настоящей работе приведены результаты рентгенофазового анализа и электронной дифракции, которые позволяют определить структурные изменения пленок СоР в зависимости от кислотности рабочих растворов.

\section{2. Технология получения образцов и методы измерений}

Исследуемые пленки толщиной $\sim 50 \mathrm{~nm}$ осаждались на стеклянные подложки с помощью метода химического восстановления Со и $\mathrm{P}$ из водных растворов $[3,4]$. Толщина сенсибилизирующего слоя $\mathrm{SnO}_{2}$ составляла $\sim 10 \AA$, толщина активирующего слоя $\mathrm{Pd} \sim 50 \AA$. Состав базового раствора включал в себя $\mathrm{CoSO}_{4} \cdot 7 \mathrm{H}_{2} \mathrm{O}(10 \mathrm{~g} / \mathrm{l})$, $\mathrm{Na}\left(\mathrm{H}_{2} \mathrm{PO}_{2}\right)$ (7.5 g/l), $\mathrm{Na}_{3} \mathrm{C}_{6} \mathrm{H}_{5} \mathrm{O}_{7}(25 \mathrm{~g} / 1)$. Известно, что на свойства ТМП СоР влияют как $\mathrm{pH}$ раствора восстановления, так и тип комплексных соединений кобальта в растворе (ацетатных, цитратных, аммиачных и др.). Более простым и технологичным представляется использование цитратных комплексов и применение в качестве щелочного реагента гидрокарбоната натрия $\mathrm{NaHCO}_{3}$ или едкого натра $\mathrm{NaOH}$, который использовался в настоящей работе. Требуемое значение $\mathrm{pH}$ задавалось добавками щелочи определенной концентрации. Ее введение приводит к нелинейному изменению кислотности растворов, как показано на рис. 1 .

Состав и толщина пленок определялись с помощью рентгеноспектрального анализа. Рентгенофазовые исследования выполнены с помощью дифрактометра ДРОН-3 с излучением $\mathrm{Cu}(1.5418 \AA)$. Микроструктура пленок

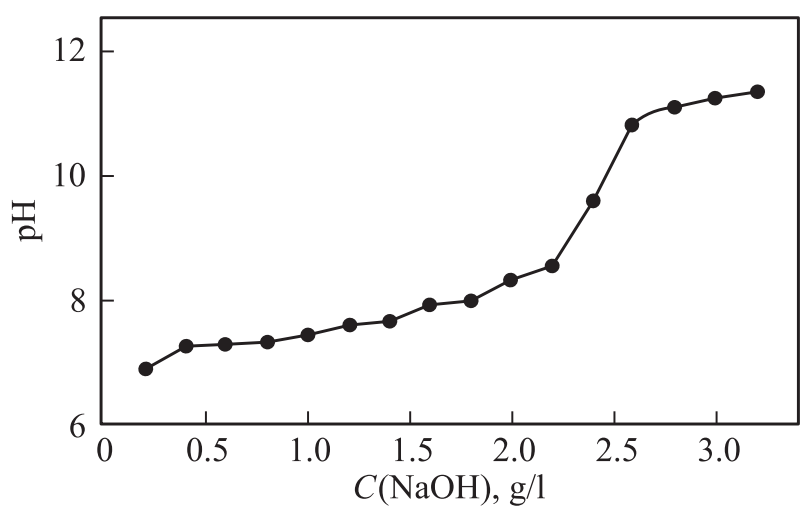

Рис. 1. Зависимость $\mathrm{pH}$ раствора от концентрации $\mathrm{NaOH}$. 


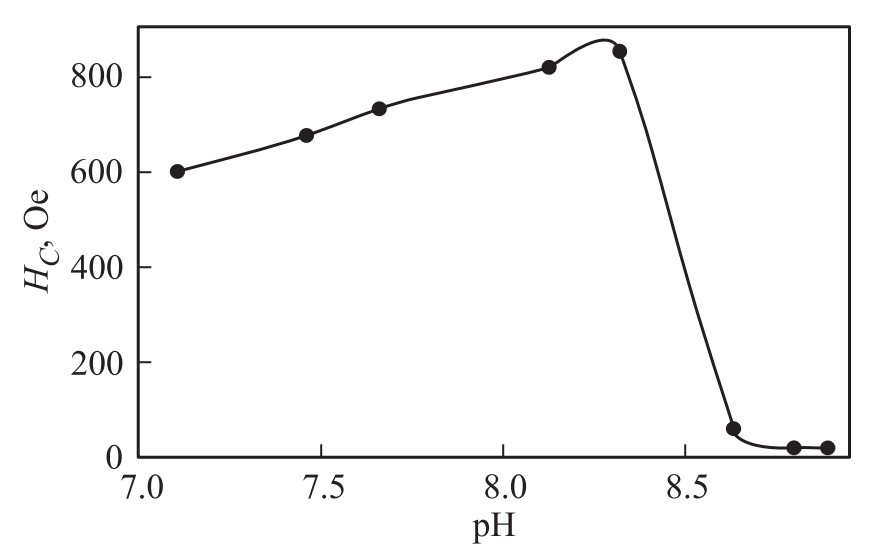

Рис. 2. Зависимость коэрцитивной силы от рН раствора. исследовалась методами просвечивающей электронной микроскопии (ПЭМ), включая просвечивающую растровую электронную микроскопию (ПРЭМ) и исследование элементного состава образцов, на микроскопе ПЭМ HT-7700 (Hitachi), оснащенном энергодисперсионным детектором X-Flash 6T/60 (Bruker). Для электронномикроскопических исследований пленки отделялись от подложки в слабом растворе плавиковой кислоты и высаживались на медные сетки.

\section{3. Результаты исследований}

Величина коэрцитивной силы пленок CoP в значительной степени зависит от $\mathrm{pH}$ рабочих растворов, из которых производилось осаждение пленок (рис. 2).
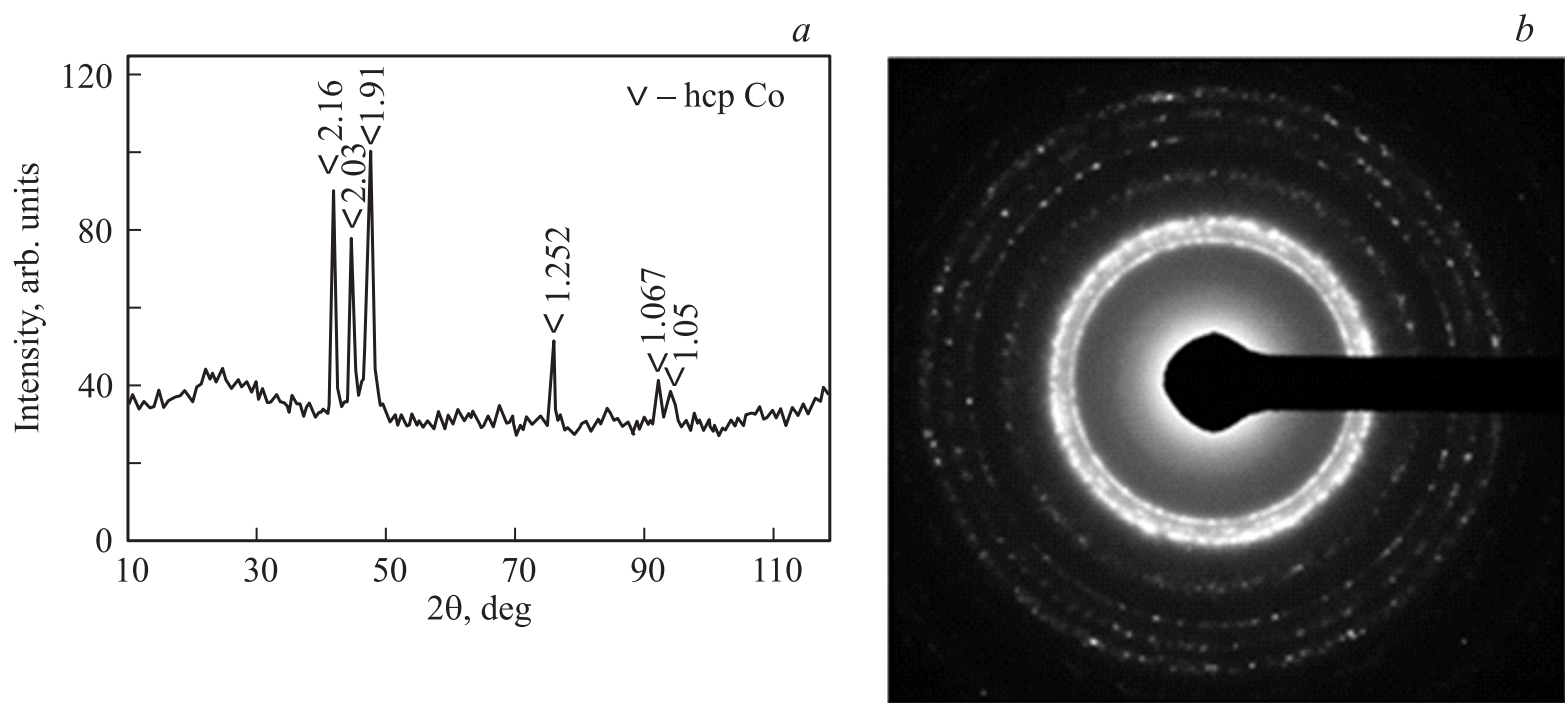

$c$
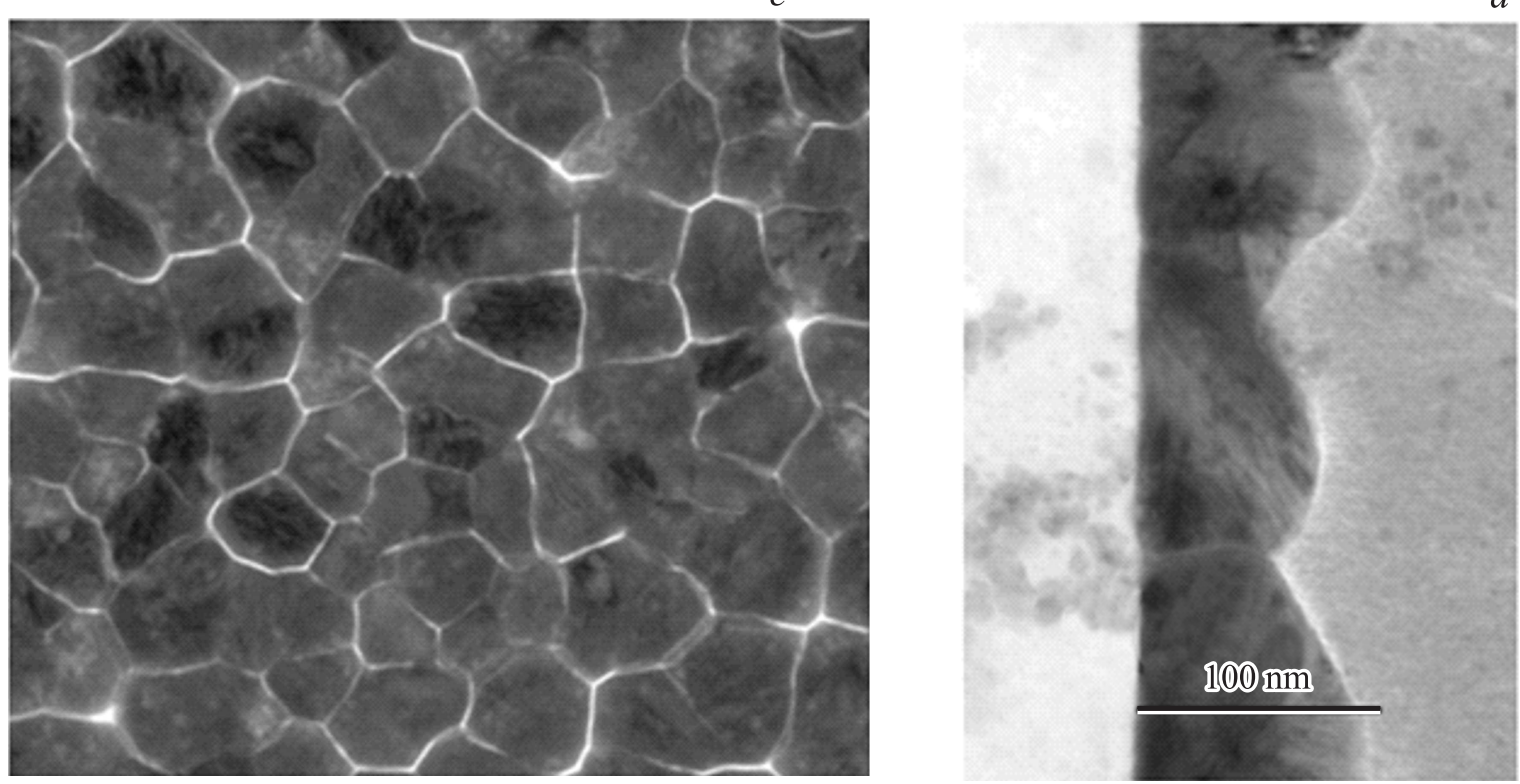

Рис. 3. Рентгенограмма $(a)$, электронограмма $(b)$, ПРЭМ-изображение $(c)$ и поперечное сечение субмикрокристаллической пленки $\mathrm{CoP}(d)$. Числа над пиками определяют межплоскостные расстояния (в $\AA$ ) в кристаллической решетке Со. 


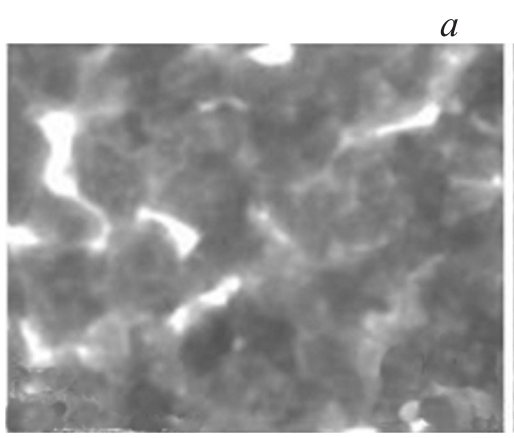

$100 \mathrm{~nm}$

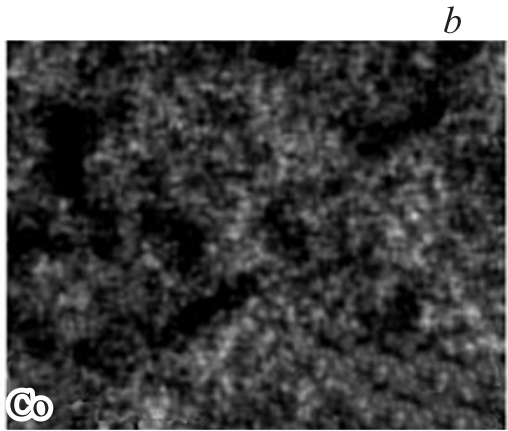

$100 \mathrm{~nm}$

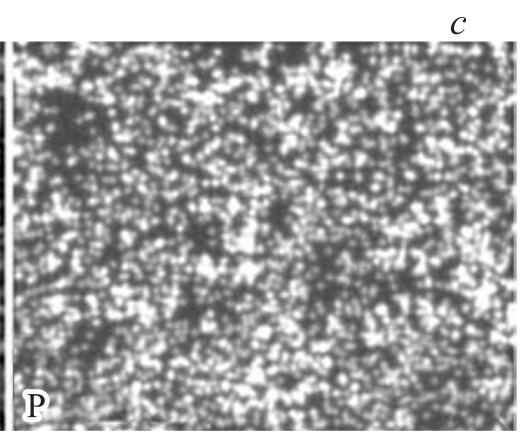

$100 \mathrm{~nm}$

Рис. 4. ПРЭМ-изображение субмикрокристаллической пленки $\operatorname{CoP}(a)$ и карты распределения $\operatorname{Co}(b)$ и $\mathrm{P}(c)$.
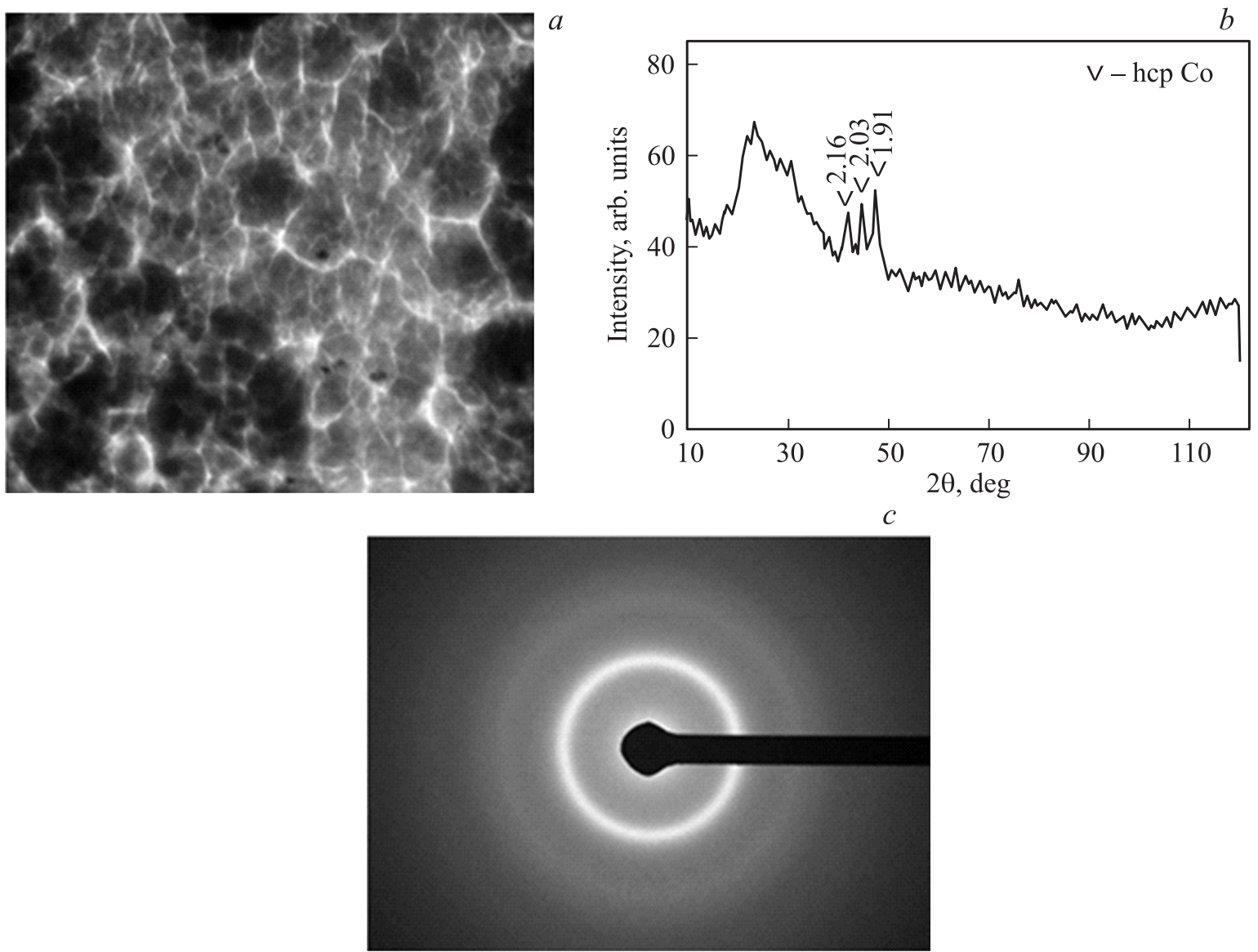

Рис. 5. ПРЭМ-изображение $(a)$, рентгенограмма $(b)$ и электронограмма нанокристаллической пленки СоР $(c)$. Числа над пиками определяют межплоскостные расстояния (в $\AA$ ) в кристаллической решетке Со.

Повышение $\mathrm{pH}$ от 7 до $~ 8.5$ приводит к линейному росту коэрцитивной силы $H_{C}$, ее величина достигает 900 Ое. Однако при дальнейшем повышении кислотности $H_{C}$ практически скачком уменьшается до нескольких эрстед. Данные особенности изменения $H_{C}$ отражают структурные изменения, которые наблюдаются в пленках СоР при изменении кислотности растворов. Как следует из данных рентгеноструктурного анализа образцов, полученных при $\mathrm{pH}<8.5$ (рис. $3, a$ ) высококоэрцитив- ная область характеризуется наличием ГПУ-фазы Со. На электронограммах образцов данного типа наблюдаются текстурированные кольца, характерные для поликристаллической структуры (рис. $3, b$ ). Относительно равная высота основных пиков отражает наличие поликристаллической структуры без преимущественного направления роста кристаллитов.

Из электронно-микроскопических снимков поверхности (рис. $3, c$ ) следует, что пленка СоР имеет мелкозер- 

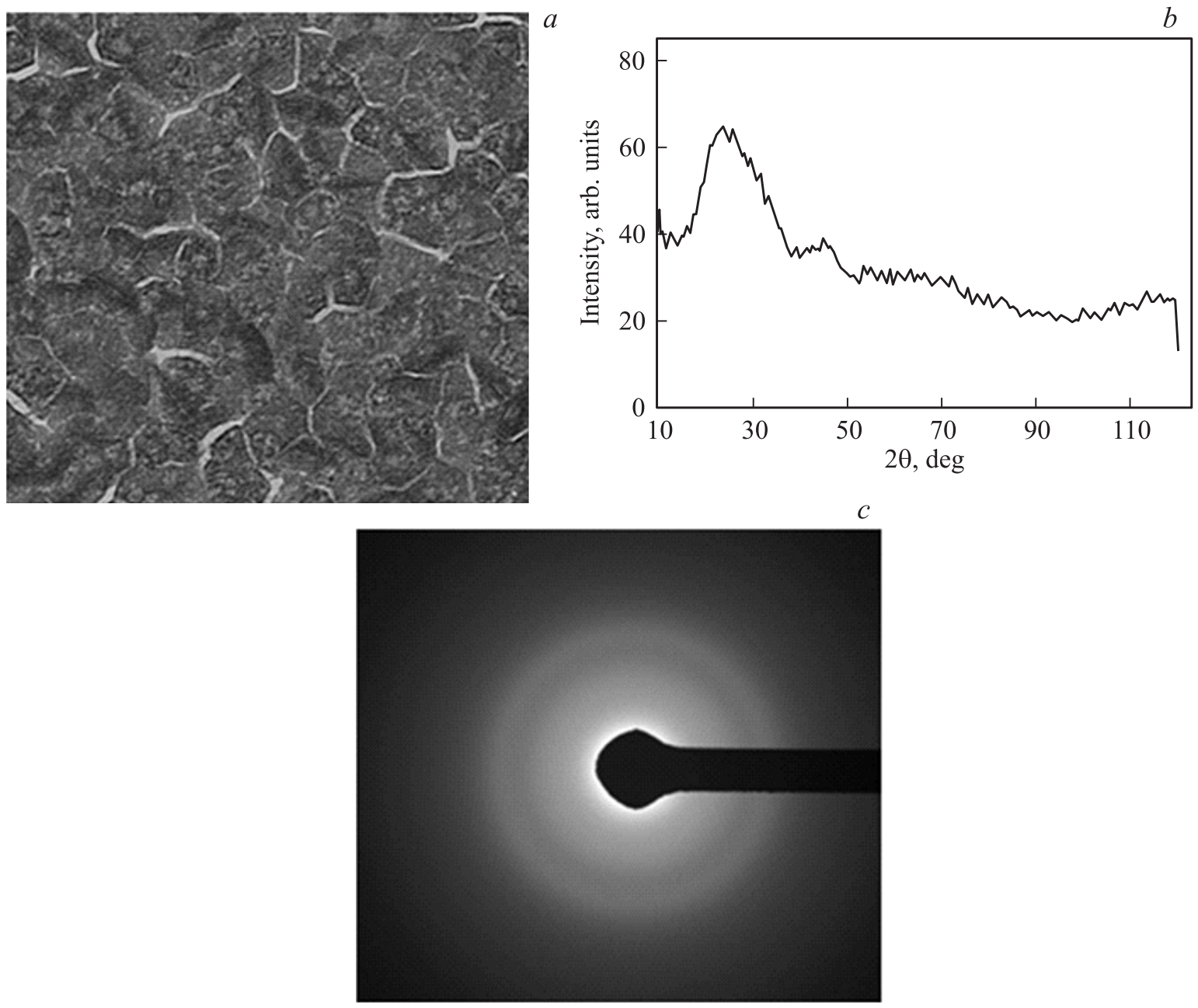

Рис. 6. ПРЭМ-изображение $(a)$, рентгенограмма $(b)$ и электронограмма аморфной пленки СоР $(c)$.

нистую структуру с размерами зерен от 50 до $70 \mathrm{~nm}$. Результаты поэлементного картирования (рис. 4) указывают на почти равномерное распределение Со и Р в зернах. При этом между соседними зернами имеются приграничные участки (на снимках они имеют вид светлых линий), которые, как следует из изображения поперечного сечения пленки (рис. $3, d$ ), разделяют кристаллиты по всей толщине. Появление таких участков связано со спецификой роста пленки из жидкой фазы. Как показано ранее [5], пленка образуется из островков. На начальном этапе они изолированы друг от друга, но с ростом толщины увеличиваются размеры зерен, и между соседними островками остается лишь тонкая прослойка. Ранее прослойки подобного вида наблюдались в пленках СоР, полученных электролитическим методом [6].

Переход в низкокоэрцитивное состояние в области $\mathrm{pH}>8.5$ соответствует изменениям структуры пленок, которые хорошо видны на электронномикроскопических снимках поверхности (рис. 5,a). На них заметно, что внутри крупных зерен, размер которых сопоставим с размером кристаллитов высококоэрцитивных пленок, наблюдаются мелкие частицы, появ- ление которых хорошо отражается на рентгенограммах (рис. 5, $b$ ) Низкие, но однозначно определяемые пики ГПУ-кобальта отражают несовершенство кристаллической решетки и составляющих ее наночастиц. На электронограммах, полученных на образцах такого типа, наблюдаются диффузно размытые рефлексы (рис. 5, c), характерные для нанокристаллических материалов. На основании анализа уширения дифракционных линий на электронограммах можно установить, что размер мелких частиц составляет от 2 до $5 \mathrm{~nm}$. На электронномикроскопических изображениях (рис. 5, $a$ ), так же как и в случае высококоэрцитивных пленок СоР, наблюдаются светлые прослойки, разделяющие более плотные структурные образования.

Данные элементного картирования показывают, что Со и $\mathrm{P}$ равномерно распределены в зернах, как и в случае высококоэрцитивных пленок.

При последующем увеличении рН происходит измельчение зерна (рис. $6, a)$, что сопровождается аморфизацией структуры, как следует из данных рентгенофазового анализа, приведенных на рис. $6, b$, и электронограммы, представленной на рис. $6, c$. 


\section{4. Обсуждение результатов}

Как показано в [7], повышение рН приводит к увеличению концентрации Р и, как следствие, к уменьшению размеров кристаллитов. На основе полученных нами данных можно установить, что существуют две области $\mathrm{pH}$ химических растворов, в пределах которых наблюдаются закономерности в структурных изменениях пленок СоР, связанных с изменением размеров зерна. При $\mathrm{pH}<8.5$ пленки образованы микроскопическими и субмикроскопическими зернами, содержащими кристаллиты Со с ГПУ-решеткой, и атомами Р. В этой области изменения $H_{C}$ в зависимости от $\mathrm{pH}$ определяются теми же физическими механизмами, что и для обычных ферромагнитных ТМП. Как показано в [5], при толщине пленки $>10 \mathrm{~nm}$ коэрцитивная сила пленок СоР обусловлена движением доменных границ (ДГ); следовательно, значение коэрцитивной силы будет определяться закреплением ДГ на неоднородностях либо критическим полем зародышеобразования. Значение коэрцитивной силы, которое связано с закреплением ДГ на немагнитных включениях в ферромагнитной матрице, можно оценить с помощью выражения, полученного Керстеном [8],

$$
H_{C}=p \frac{K_{\text {eff }}}{M s} \beta^{n},
$$

где параметр $p \propto 1 / d, \beta-$ концентрация включений, $M_{s}$ - намагниченность насыщения, $K_{\mathrm{eff}}$ - эффективная константа анизотропии, $n$ - показатель степени, принимающий положительные значения. Критическое поле зародышеобразования, при достижении которого происходит перемагничивание всего объема образца, определено Дерингом [9]

$$
H_{s}=H_{0}+\frac{\gamma}{M_{s} d}
$$

где $\gamma$ - энергия ДГ, $d-$ размер зерна, $H_{0}$ - дополнительное поле, связанное с потенциальными барьерами, препятствующими движению ДГ.

Оба рассматриваемых механизма, которые обусловливают магнитный гистерезис при перемагничивании исследуемых пленок, могут являться причиной роста коэрцитивной силы при увеличении кислотности раствоpa в области малых значений $\mathrm{pH}$, так как повышение концентрации фосфора приводит к росту количества немагнитных включений и уменьшению размеров ферромагнитных зерен Сo.

Причины аномального уменьшения $H_{C}$ при переходе пленки от субмикрокристаллического состояния в нанокристаллическое в области $\mathrm{pH}>8.5$, судя по всему, те же, что и в нанокристаллических магнитомягких сплавах с гранулированной структурой [10]. В том случае, если размер зерна становится меньше критической величины $d_{c}$, то в таких материалах существенную роль играет обменная энергия, которая понижает вклад магнитной анизотропии случайно ориентированных зерен в общую энергию. Значение $d_{c}$ определяется балансом этих двух энергий и составляет величину порядка ширины ДГ ферромагнетика

$$
L_{0}=\sqrt{\frac{A}{K_{1}}},
$$

где $A$ - константа обмена, $K_{1}-$ константа анизотропии.

Для пленок $\mathrm{CoP}$ значения $K_{1}=4.3 \cdot 10^{5} \mathrm{~J} / \mathrm{m}^{3}$ (ГПУСо [11]) и $A \sim 10^{-11} \mathrm{~J} / \mathrm{m}$ (сплав $\mathrm{CoP}[12]$ ), тогда из (3) находим, что критический размер зерна должен составлять $\sim 4.8 \mathrm{~nm}$, что соответствует размерам кристаллитов в области перехода.

\section{5. Заключение}

На основании полученных данных можно сделать следующие выводы. В области малой кислотности с $\mathrm{pH}<8.5$ пленки СоР состоят из субмикрокристаллических зерен с ГПУ-решеткой. До этой кислотности раствора коэрцитивная сила увеличивается за счет роста количества немагнитных включений и уменьшения размеров зерна. При $\mathrm{pH}>8.5$ падение $H_{C}$ связано с резким уменьшением эффективной анизотропии при переходе пленки от субмикрокристаллического в нанокристаллическое состояние. Можно также заключить, что пленки $\mathrm{CoP}$, полученные в области $\mathrm{pH} \sim 8.5$, обладают свойствами, характерными для компактных нанокристаллических материалов.

Авторы выражают благодарность Г.В. Бондаренко за помощь в проведении рентгеноспектральных исследований.

\section{Список литературы}

[1] В.В. Бондарь. Итоги науки. Сер. „Электрохимия-1966“. ВИНИТИ, М. (1968). С. 56

[2] А.В. Чжан, Т.Н. Патрушева, С.А. Подоржняк, В.А. Середкин, Г.Н. Бондаренко. Изв. РАН. Сер. физ. 80, 692 (2016).

[3] A. Brenner, G. Riddell. J. Res. Natl. Bur. Stand. 39, 385 (1947).

[4] O.M. Glenn, B.H Juan. Electroless plating: fundamentals and applications. Orlando (1990). $401 \mathrm{p}$.

[5] А.В. Чжан, Г.С. Патрин, С.Я. Кипарисов, В.А. Середкин, М.Г. Пальчик. ФММ 109, 650 (2010).

[6] Т.А. Точитский, Л.В. Немцевич. Электрохимия 34, 957 (1998).

[7] N. Lu, J. Cai, L. Li. Surface Coatings Technol. 206, 4822 (2012).

[8] M. Kersten. Z. Phys. 124, 714 (1948).

[9] В. Деринг. УФН 22, 78 (1939).

[10] G. Herzer. In: Handbook of magnetic materials / Ed. K.H.J. Buchow. Elsevier Science B.V. (1997). P. 415.

[11] С.В. Вонсовский. Магнетизм. Наука, М. (1971). 1032 с.

[12] Р.С. Исхаков, Р.Г. Хлебопрос. Препринт ИФ им. Л.В. Киренского СО АН СССР. Красноярск (1980). 61 c. 